\title{
Phylogenetic Relationships of Eublepharid Geckos (Reptilia: Squamata): A Molecular Approach
}

\author{
Hidetoshi Ota ${ }^{1 *}$, Masanao Honda ${ }^{2}$, Mari Kobayashi $^{2}$, Showichi Sengoku ${ }^{3}$, \\ and Tsutomu Hikida ${ }^{2}$ \\ ${ }^{1}$ Tropical Biosphere Research Center, University of the Ryukyus, Nishihara, \\ Okinawa 903-0213, Japan, \\ ${ }^{2}$ Department of Zoology, Graduate School of Science, Kyoto University, Sakyo-ku, \\ Kyoto 606-8502, Japan and \\ ${ }^{3}$ Japan Wildlife Research Center, Yushima 2-29-3, Bunkyo-ku, \\ Tokyo 113-0034, Japan
}

\begin{abstract}
Phylogenetic analyses were carried out for representatives of all eublepharid genera and a few other gekkonoid taxa using sequence data for 879 base pairs of mitochondrial $12 S$ and $16 S$ ribosomal RNA genes. Neighbor-joining (NJ) distance analysis of the data suggested independent great divergences of Coleonyx and Aeluroscalabotes, and monophyly of the remainder within Eublepharidae (bootstrap proportion $[\mathrm{BP}]=76 \%$ ). Of the latter, the two African genera, Hemithecony $x$ and Holodactylus, were almost certainly monophyletic altogether $(\mathrm{BP}=99 \%)$, whereas their sister-group relationship with Eublepharis received a weaker, but still substantial support ( $\mathrm{BP}=68 \%$ ). Within Goniurosaurus kuroiwae, G. $k$. splendens first diverged from the remainder ( $\mathrm{BP}=100 \%)$, followed by $G$. $k$. kuroiwae from the northern part of Okinawajima $(\mathrm{BP}=100 \%)$ : $G$. k. kuroiwae from the southern part of Okinawajima and G. . orientalis, differing from each other at only seven bases, diverged finally $(B P=99 \%)$. Parsimony analysis yielded results consistent with those of $N J$ analysis with respect to the monophyly of the two African genera and relationships within G. kuroiwae, but retained the other relationships within Eublepharidae unresolved. Our results, while showing no serious discrepancies with the relationships among eublepharid genera hypothesized from morphological data, cast a serious doubt to the currently accepted population systematics within G. kuroiwae. Furthermore, results of both analyses suggested a closer affinity of Diplodactylinae (as represented by Rhacodactylus trachyrhynchus) with Eublepharidae, rather than with Gekkoninae. Our study lends a robust support to the Laurasian origin of the family Eublepharidae.
\end{abstract}

\section{INTRODUCTION}

Kluge (1987), based on the cladistic analysis of morphological characters, recognized "eyelid geckos" classified to the subfamily Eublepharinae of the family Gekkonidae to that date (Kluge, 1967), as constituting a single primitive lineage distant from all other members of the microorder Gekkota (Fig. 1). He thus revalidated family Eublepharidae Boulenger, 1883, to accommodate all eyelid geckos that sporadically occur in Eurasia, Africa and North America.

Also on the basis of the cladistic analysis of morphological characters, Grismer (1988), while confirming the monophyly of the eublepharid geckos, formulated a detailed, comprehensive phylogenetic hypothesis for the family (Fig. 2) and revised the infrafamilial classification accordingly. Through this

\footnotetext{
* Corresponding author: Tel. +81-98-895-8937; FAX. +81-98-895-8576. E-mail: ota@sci.u-ryukyu.ac.jp
}

and two subsequent taxonomic works (Grismer, 1989, 1991), 18 species belonging to six genera of two subfamilies have been recognized for the family Eublepharidae.

A few other studies demonstrated considerable chromosomal and eco-physiological variations among some eublepharid geckos (e.g., Murphy, 1974; Ota et al., 1987; Dial and Grismer, 1992), and these predict the effectiveness of approaches other than the external and anatomical analyses to the eublepharid phylogeny. For the improvement of a given phylogenetic hypothesis formulated on the basis of a certain set of characters, testing by using a different character set would be highly effective. Nevertheless, no approaches other than the above-mentioned morphological ones have ever been attempted toward the comprehensive phylogeny of this family or its relationship with other gekkotan groups.

We partially sequenced mitochondrial DNA (mtDNA) for representatives of all eublepharid genera and a few of other major groups of Gekkota (subfamilies Gekkoninae and Diplodactylinae of the family Gekkonidae), and analysed 


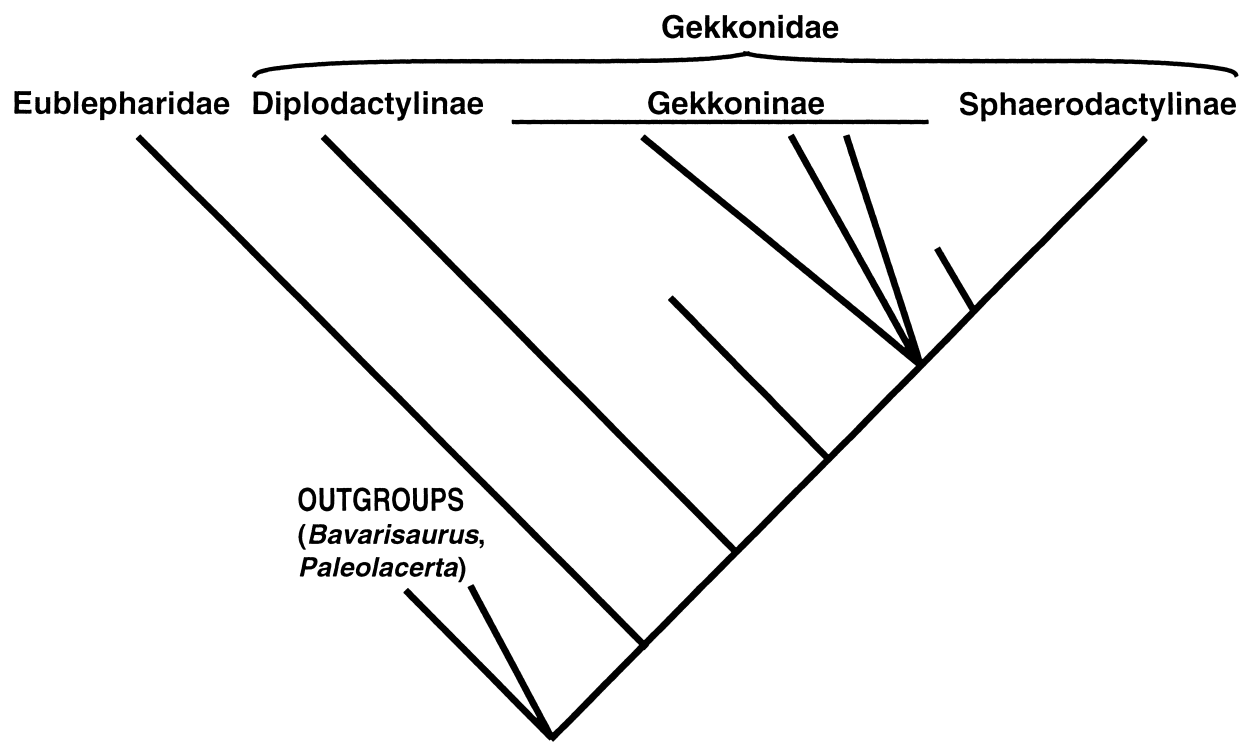

Fig. 1. Cladistic relationships of the major groups of Gekkota (exclusive of Pygopodidae) hypothesized by Kluge (1987). He also argued for (and depicted) the sister-group relationship of Pygopodidae with Diplodactylinae, but this account is not fully accepted (e.g., Estes et al., 1988).

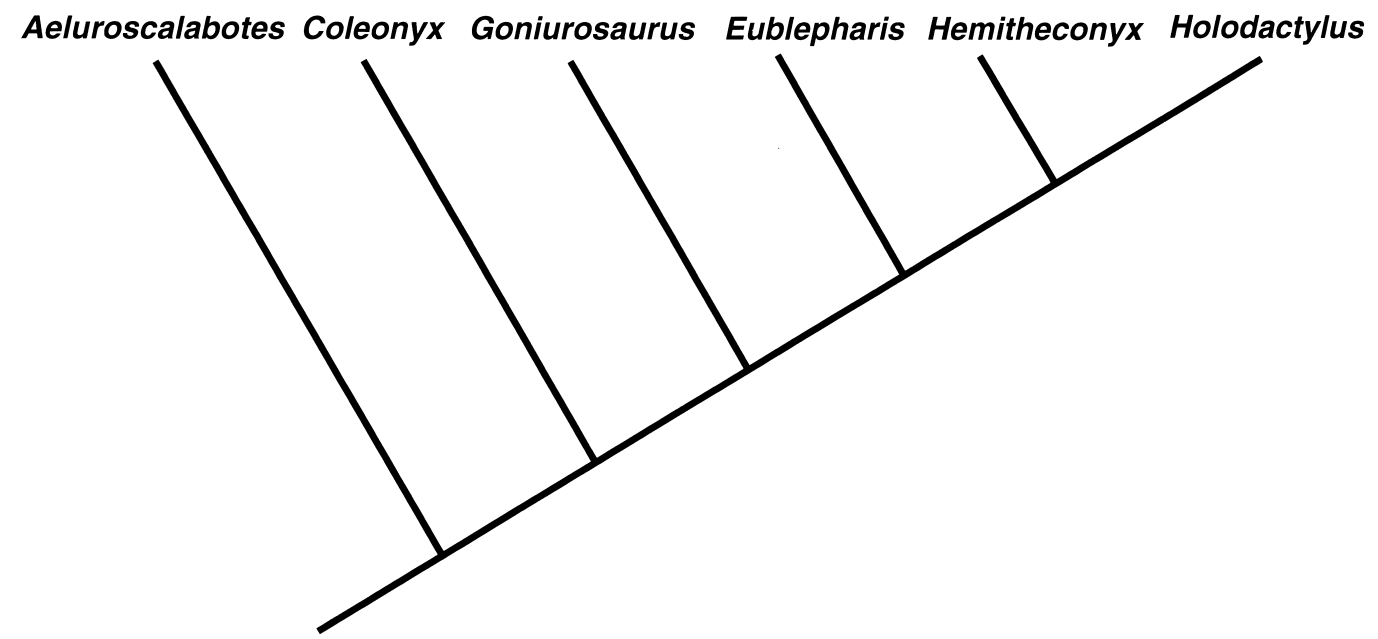

Fig. 2. Cladistic relationships of the eublepharid genera hypothesized by Grismer (1988).

resultant sequences phylogenetically. In this paper, we compare our results with results of morphological analyses by previous authors, and discuss their systematic and biogeographical implications.

\section{MATERIALS AND METHODS}

A total of 17 specimens (three subspecies and seven species) representing all of the six eublepharid genera were used. Of these, six specimens of Goniurosaurus kuroiwae and two specimens of Aeluroscalabotes felinus were sampled in the field. The other specimens were obtained from pet dealers in life or in fresh dead state. These included two obviously conspecific eublepharid specimens of unknown origins that showed morphological features characteristic of Goniurosaurus (as defined by Grismer [1988]), but were distinct from either of the two known species of the genus (i.e., G. kuroiwae and G. lichtenfelderi: Grismer, 1988) (Fig. 3). We henceforth refer to

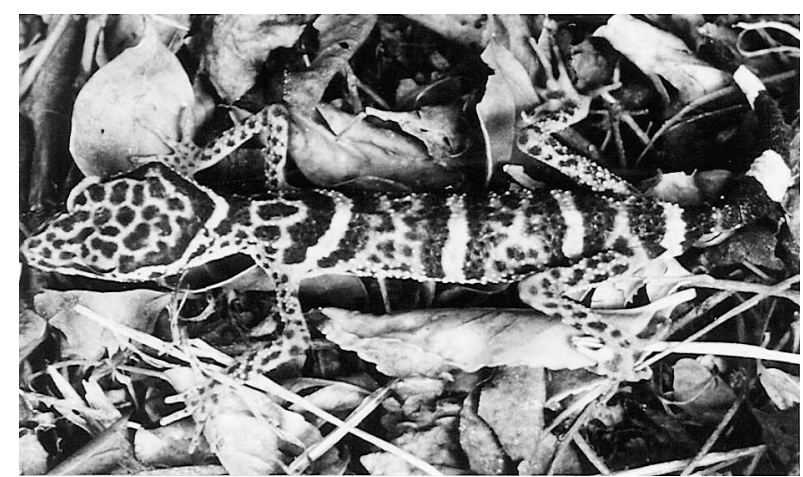

Fig. 3. Apparently undescribed species of Goniurosaurus used in this study. 
these specimens as G. sp. One diplodactyline (Rhacodactylus trachyrhynchus) and two gekkonine geckos (Gekko gecko and Cyrtodactylus intermedius) of the family Gekkonidae were also subjected to this study. As outgroups, two scincids (Eumeces latiscutatus and Lygosoma bowringii) and one iguanid species (Iguana iguana) were chosen as representatives of Autarchoglossa (an extant sistergroup of Gekkota) and a more basal lineage (Estes et al., 1988), respectively. Voucher specimens are deposited in the Department of Zoology, Kyoto University (KUZ: see Appendix-1).

Livers, removed from anesthetized or dead specimens and stocked at $-80^{\circ} \mathrm{C}$, were used for DNA extraction. Each sample was processed for sequencing of $12 \mathrm{~S}$ and $16 \mathrm{~S}$ ribosomal RNA (rRNA) genes of mitochondrial DNA (mtDNA) following the method by Wada et al. (1992) as modified by Honda et al. (1999). These genes, functionally important and thus are supposedly fairly conservative, are expected to be informative for divergence back to about 300 million years ago (MYA) at maximum (Mindell and Honeycutt, 1990). Thus, sequence variation in these genes seems to be suitable for the phylogenetic reconstruction of extant Gekkota, which divergence is considered to have initiated some 180 MYA (Kluge, 1987).

Alignments for DNA sequences were determined based on maximum nucleotide similarity. Using the aligned sequences, we eliminated gap sites and prepared a pairwise matrix of distance by Kimura's (1980) two-parameter model for transition/transversion bias. The matrix was then subjected to the analysis by the neighbor-joining $(\mathrm{NJ})$ method (Saitou and Nei, 1987) using Clustal W (Thompson et al., 1994). Degrees of supports for internal branches of each tree were assessed by 1,000 bootstrap pseudoreplications (Felsenstein, 1985). Parsimony analysis was also performed using the Heuristic algorithum of PAUP (version 3.11: Swofford, 1993). In this analysis, each nucleotide base was regarded as a character and four kinds of salts as different character states. The result of this analysis was expressed as a $50 \%$ majority-rule consensus tree. In both analyses, each specimen was set as constituting a single OTU by itself.

The interpretation of bootstrap proportions (BPs) is still controvertial (e.g., Felsenstein and Kishino, 1993; Hillis and Bull, 1993). We tentatively postulated BPs $\geq 90 \%$ as strong support, $70 \leq B P s<90 \%$ as moderate support, $50 \leq \mathrm{BPs}<70 \%$ as constituting limited evidence of monophyly, and BPs $<50 \%$ as insufficent support for monophyly, following Shaffer et al. (1997).

\section{RESULTS}

Aligned sequences from two mtDNA genes are presented in Appendix-2. The 12S rRNA fragment consisted of 406 total aligned sites, of which $253(62.3 \%)$ were variable. For the

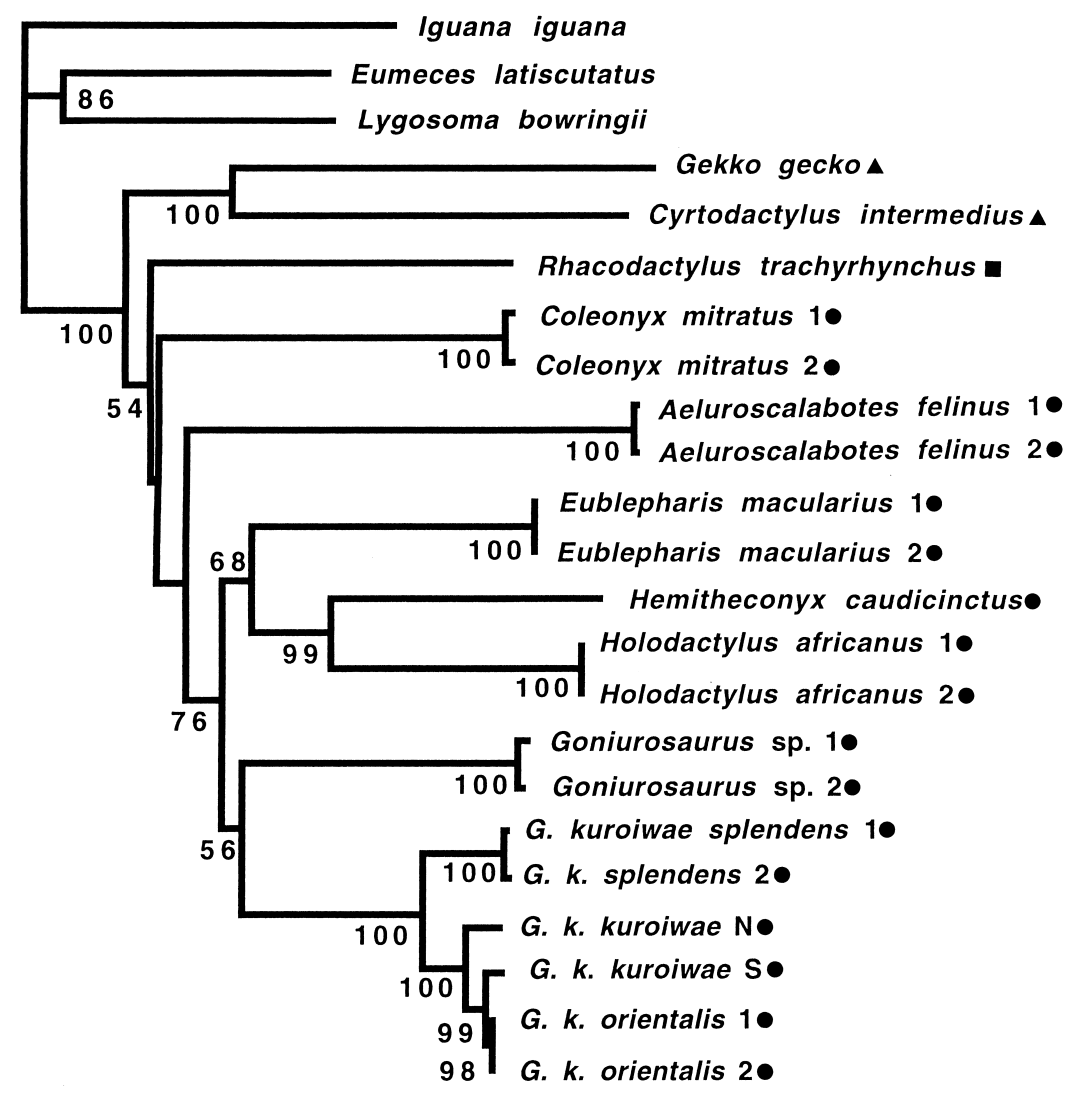

0.1

Fig. 4. NJ dendrogram deriving from Kimura's (1980) distance matrix from $12 S$ and $16 S$ rRNA sequence data. Numbers at branches indicate bootstrap proportions in 1,000 bootstrap pseudoreplications. Of the ingroup taxa, those belonging to the family Eublepharidae, and subfamilies Gekkoninae and Diplodactylinae of the family Gekkonidae are denoted by circles, triangles and a rectangle, respectively. N and $S$ following $G$. $k$. kuroiwae indicate that those specimens were from the northern and the southern parts of Okinawajima, respectively (see Appendix-1 for further details). For each of other species/subspecies, different individuals, when examined, are discriminated by arabic numerals (1,2). Scale bar equals 0.1 of the distance. 
16S rRNA fragment, there were 473 total sites, of which 259 $(54.8 \%)$ were variable. Nucleotide replacements of the eublepharids with a diplodactyline and gekkonines varied from 174 base pairs (bp) (Holodactylus africanus vs Rhacodactylus trachyrhynchus) to $200 \mathrm{bp}$ (Goniurosaurus sp. vs $R$. trachyrhynchus), and from 202 bp ( $H$. africanus vs Cyrtodactylus intermedius) to $236 \mathrm{bp}$ (G. kuroiwae kuroiwae vs Gekko gecko), respectively, whereas those between the latter two groups were from 197 bp (C. intermedius vs $G$. gecko) to $239 \mathrm{bp}$ ( $R$. trachyrhynchus vs G. gecko). Within Eublepharidae, the intergeneric and intrageneric replacements ranged from 137 bp (Hemitheconyx caudicinctus vs Holodactylus africanus) to $200 \mathrm{bp}$ (Aeluroscalabotes felinus vs $H$. africanus), and from $7 \mathrm{bp}$ (G. k. kuroiwae vs G. k. orientalis) to $159 \mathrm{bp}$ (G. k. kuroiwae vs G. sp.), respectively.

Fig. 4 shows the NJ dendrogram derived from the OTUdistance matrix. In this analysis, no sufficient supports were obtained for the monophyly of the Eublepharidae, because of the inclusion of $R$. trachyrhynchus (Diplodactylinae of Gekkonidae) to the otherwise eublepharid cluster. Within Eublepharidae, Coleonyx and Aeluroscalabotes showed great, independent divergences, whereas the others appeared monophyletic $(\mathrm{BP}=76 \%)$. Sister-group relationships of the two Afri- can genera (Hemitheconyx and Holodactylus) of the latter was strongly supported $(\mathrm{BP}=98 \%)$, whereas their sister-group relationships with Eublepharis received a weaker support $(\mathrm{BP}=68 \%)$. On the other hand, monophyly of Goniurosaurus was even more weakly supported $(B P=56 \%)$. All conspecific/ consubspecific combinations received $98-100 \%$ BP supports. Of $G$. kuroiwae subspecies/populations examined here, G. $k$. splendens first diverged, and then did G. k. kuroiwae from the northern part of Okinawajima: G. k. kuroiwae from the southern part of Okinawajima and G. k. orientalis constituted a minimum monophyletic unit with high BP value (99\%).

Results of the parsimony analysis showed no apparent inconsistensy with the relationships suggested by the NJ dendrogram. As are depicted in Fig. 5, relationships resulting from this analysis weakly but still substantially supported the closer diplodactyline affinity to eublepharids than to gekkonines (BP $=64 \%$ ), and strongly supported the monophyly of African eublepharids (97\%), greatest divergence of G. k. splendens among the conspecifics, and closer affinity of $G$. k. kuroiwae from southern Okinawajima to $G$. k. orientalis than to $G$. $k$. kuroiwae from northern Okinawajima ( $\mathrm{BP}=100 \%$ for both).

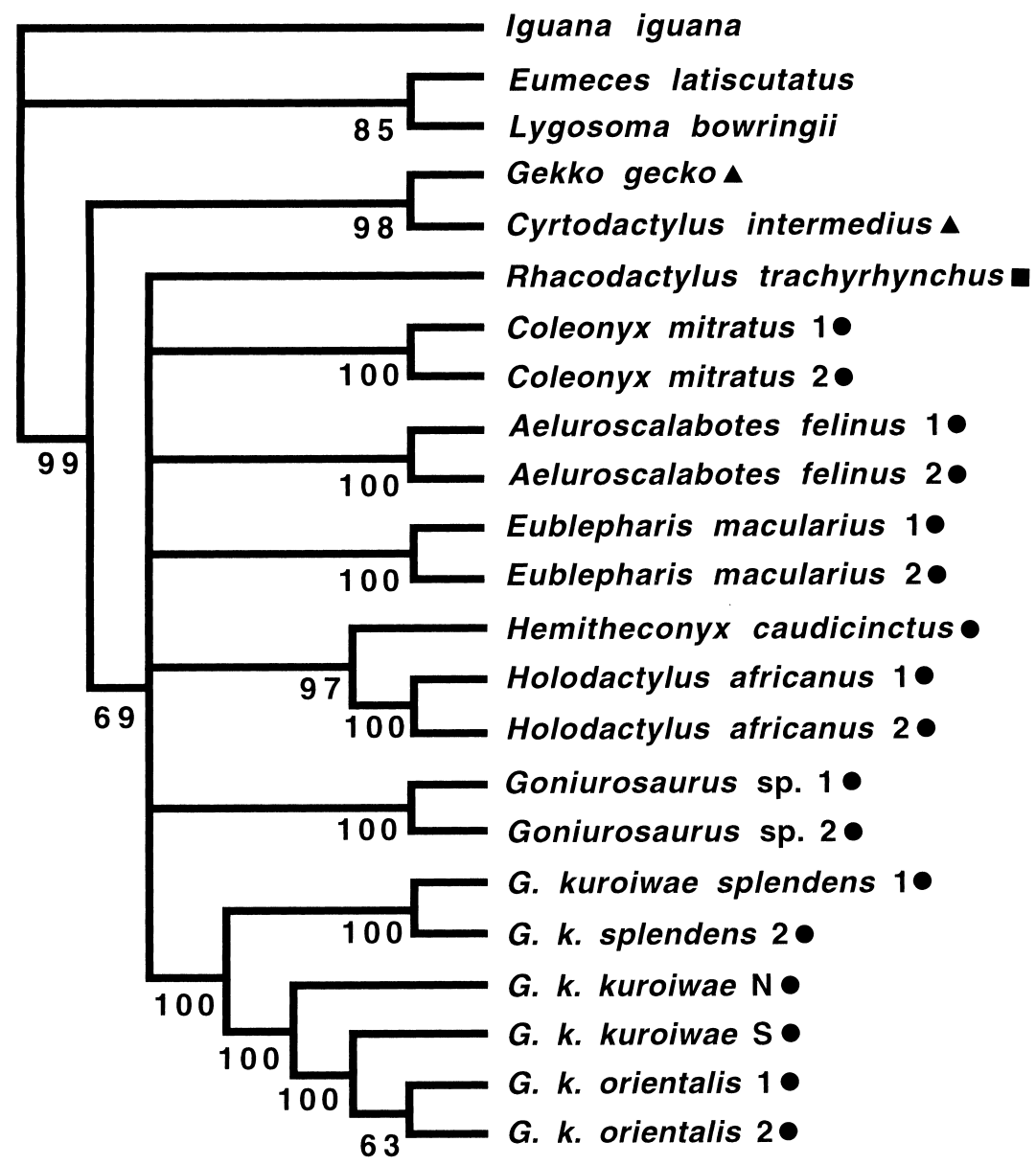

Fig. 5. The majority-rule consensus tree deriving from parsimony analysis using nucleotide bases of $12 \mathrm{~S}$ and $16 \mathrm{~S}$ rRNA genes as characters and the four kinds of salts as different character states. See Fig. 4 for explanations of denotations. 


\section{DISCUSSION}

As far as the intergeneric phylogeny within Eublepharidae is concerned, results of the present analyses showed no serious contradictions with the previous hypothesis formulated on the basis of a cladistic analysis of morphological data (Grismer, 1988) (Fig. 2). Our results, nevertheless, did not support the initial, most fundamental divergence of Aeluroscalabotes from the remaining eublepharids, which let Grismer (1988) establish the monotypic subfamily Aeluroscalabotinae against Eublepharinae. Further, more comprehensive analysis is needed to verify the validity of these subfamilies from the phylogenetic view point.

The relatively poor support for the closest affinity between the two Goniurosaurus species examined may be attributable to their relatively long isolation as is also implied by the highly relict distribution of the genus (Ota, 1998). This ad hoc assumption needs verifications by incorporating data for the other Goniurosaurus species, G. lichtenfelderi, into future analyses.

The relationship among populations of G. kuroiwae did not agree with their assignments to morphologically defined subspecies (Grismer et al., 1994), because it strongly suggests the genealogical proximity of the southern Okinawajima population of G. k. kuroiwae with G. k. orientalis rather than with the consubspecific population in the northern part of the island. The habitat of $G$. kuroiwae is largely confined to areas covered with humid vegetations, such as primary and well recovered secondary forests (Matsui and Ota, 1999). Thus, the broad, dry vegetational zone in the middle of Okinawajima (AJLSA, 1994), from which no G. k. kuroiwae have ever been found (Matsui and Ota, 1999), might have possibly been intervening the gene flow between populations on both sides. The small, but still substantial, genetic divergence between the G. k. kuroiwae populations from the northern and southern parts of the island seems to reflect a certain duration of such an isolation. Considerably close affinity of the southern Okinawajima population of G. k. kuroiwae with G. k. orientalis is puzzling, because, as long as the current geography is concerned, locality of the sample of orientalis examined here (lejima) is closer to the northern part of Okinawajima. This may reflect a closer geohistorical relationship of lejima with the southern part of Okinawajima than with the northern part.

The closer relationship of a diplodactyline species ( $R$. trachyrhynchus) with eublepharids than with gekkonines (Gekko gecko and Cyrtodactylus intermedius), suggested by both $\mathrm{NJ}$ and parsimony analyses, is also puzzling because such a relationship needs to presume occurrences of either parallel derivations of a number of advanced character states shared by the diplodactyline and gekkonine geckos, or reversals of a number of characters to primitive states in the eublepharid lineage (Kluge, 1987; Grismer, 1988). Further analyses using more samples especially of representatives of Sphaerodactylinae (the other gekkonid subfamily: see Fig. 1 ), as well as of additional gekkonine and diplodactyline species, are strongly desired to confirm such diplodactyline rela- tionship.

Kluge (1967) assumed that Southeast Asia was the center of origin of all extant gekkotan lineages and that diplodactyline geckos, having emerged there from eublepharid ancestor, dispersed into Australia through the Indo-Australian Archipelago during the late Mesozoic. With the subsequent general acceptance of the "mobile continents" and the revision of the cladistic hypothesis of Gekkota, he formulated a completely different scenario, in which divergences of eublepharids and diplodactylines from the others are, respectively, attributed to the breakup of Pangaea into Laurasia and Gondowanaland in 180 MYA, and more tentatively to the Africa-India and Australia-New Zealand separation of the latter in 85 MYA (Kluge, 1987). The secondary dispersal is assumed to explain the current occurrence of a few eublepharid genera in the Gondowana region (i.e., Hemitheconyx and Holodactylus in Africa) in this hypothesis. In the same year, King (1987a, b), based on the chromosomal and immunodistance data, and the fact that all major extant lineages occur in the Gondowana region, argued for the Gondowana origin of the whole Gekkota (Gekkonidae in his use). He considered the current Laurasian eublepharids (e.g., Aeluroscalabotes in Southeast Asia and Coleonyx in North America) as deriving from the secondary dispersal.

Based on a few morphological characters, Borner (1981) argued that Holodactylus in Africa is most primitive among the eublepharid genera. This account seems to lend some supports to King's (1987a, b) hypothesis. However, our results, along with results of morphological analysis by Grismer (1988), strongly suggest the most primitive status for the Laurasian Aeluroscalabotes and Coleonyx, and, contrary to the view of Borner (1981), most recent divergence of the Gondowanan Holodactylus, as well as of Hemitheconyx. These stongly suggest the Laurasian origin of the eublepharid geckos as was hypothesized by Kluge (1987). Closer affinity of Rhacodactylus with eublepharids suggested in our results may be indicative of the past dispersal of the diplodactyline ancestor to the Australia-New Zealand region directly from Laurasia (contra Kluge [1987] and King [1987a, b]).

\section{ACKNOWLEDGMENTS}

We thank M. Matsui, K. Araya, M. Toda, S. Iwanaga, S. Tanaka and $\mathrm{M}$. Toyama for helping with field sampling, M. Yokota for literature, and Y. Yasukawa for the arrangement to obtain fresh dead material from pet dealers for free of charge. We are also much indebted to N. Satoh, who allowed us to use his laboratory facility for mtDNA sequencing. Experiments were also carried out using the facility of the Kyoto University Museum. This research was partially supported by Grants-in-Aid from Japan Ministry of Education, Science, Sports and Culture (Overseas Researches No. 03041044 to T. Hidaka and No. 04041068 to M. Matsui, and Basic Researches C-09839024 to $\mathrm{H}$. Ota and C-10836010 to T. Hikida), and a grant from the Fujuwara Natural History Foundation (to $\mathrm{H}$. Ota). Financial support was also provided by Japan Agency of Environment, under the project entitled, "Genetic Diversity Survey of Japanese Wildlife".

Goniurosaurus kuroiwae has been designated as a natural monument of Okinawa Prefecture and the handling of this species is strictly 
regulated by law. This research was carried out under the permission from the Section of Culture, Board of Education, Okinawa Prefectural Government, through the courtesy of M. Toyama, Y. Chigira and K. Tomari.

\section{REFERENCES}

All Japan Land Survey Association (AJLSA) (ed.) (1994) Land Conservation Map: Okinawa Prefecture. AJLSA, Japan (in Japanese)

Borner AR (1981) The genera of Asian eublepharine geckos and a hypothesis of their phylogeny. Misc Art Saurol Cologne 9: 1-14

Dial BE, Grismer LL (1992) A phylogenetic analysis of physiologicalecological character evolution in the lizard genus Coleonyx and its implications for historical biogeographic reconstruction. Syst Biol 41: 178-195

Estes R, de Queiroz K, Gauthier J (1988) Phylogenetic relationships within Squamata. In "Phylogenetic Relationships of the Lizard Families" Ed by Estes R and Pregill G, Stanford University Press, Stanford, pp 119-281

Felsenstein J (1985) Confidence limits on phylogenies: An approach using the bootstrap. Evolution 39: 783-791

Felsenstein J, Kishino H (1993) Is there something wrong with the bootstrap on phylogeny? A reply to Hillis and Bull. Syst Biol 42: 193-200

Grismer LL (1988) Phylogeny, taxonomy, classification, and biogeography of eublepharid geckos. In "Phylogenetic Relationships of the Lizard Families" Ed by Estes R and Pregill G, Stanford University Press, Stanford, pp 369-469

Grismer LL (1989) Eublepharis ensafi Baloutch and Thireau, 1986: A junior synonym of $E$. angramainyu Anderson and Leviton, 1966. J Herpetol 23: 94-95

Grismer LL (1991) Cladistic relationships of the lizard Eublepharis turcmenicus (Squamata: Eublepharidae). J Herpetol 25: 251253

Grismer LL, Ota H, Tanaka S (1994) Phylogeny, classification, and biogeography of Goniurosaurus kuroiwae (Squamata: Eublepharidae) from the Ryukyu Archipelago, Japan, with description of a new subspecies. Zool Sci 11: 319-335

Hillis DM, Bull JJ (1993) An empirical test of bootstrapping as a method for assessing confidence in phylogenetic analysis. Syst Biol 42: 182-192

Honda M, Ota H, Kobayashi M, Nabhitabhata J, Yong H-S, Hikida T (1999) Phylogenetic relationships of the flying lizards, genus Draco (Reptilia, Agamidae). Zool Sci 16: 535-549

Kimura M (1980) A simple method for estimating evolutionary rate of base substitutions through comparative studies of nucleotide sequences. J Mol Evol 16: 116-120
King M (1987a) Chromosomal evolution in the Diplodactylinae (Gekkonidae: Reptilia). I. Evolutionary relationships and patterns of change. Aust J Zool 35: 507-531

King M (1987b) Origin of the Gekkonidae: Chromosomal and albumin evolution suggests Gondowanaland. Search 18: 252-254

Kluge AG (1967) Higher taxonomic categories of gekkonid lizards and their evolution. Bull Amer Mus Nat Hist 135: 1-59

Kluge AG (1987) Cladistic relationships in the Gekkonoidea (Squamata, Sauria). Misc Publ Mus Zool, Univ Michigan 173: 153

Matsui M, Ota H (1999) Red Data Book of Japan. Amphibians and Reptiles. Japan Agency of Environment, Tokyo (in Japanese with English summary) (in press)

Mindell DP, Honeycutt RL (1990) Ribosomal RNA in vertebrates: Evolution and phylogenetic application. Ann Rev Ecol Syst 21: 541-566

Murphy RW (1974) A new genus and species of eublepharine gecko (Sauria: Gekkonidae) from Baja California, Mexico. Proc California Acad Sci 40: 87-92

Ota H (1998) Geographic patterns of endemism and speciation in amphibians and reptiles of the Ryukyu Archipelago, Japan, with special reference to their paleogeographical implications. Res Popul Ecol 40: 189-204

Ota H, Matsui M, Hikida T, Tanaka S (1987) Karyotype of a gekkonid lizard, Eublepharis kuroiwae kuroiwae. Experientia 43: 924-925

Saitou N, Nei M (1987) The neighbor -joining method: A new method for reconstructing phylogenetic trees. Mol Biol Evol 4: 406-425

Shaffer HB, Meylan P, McKnight ML (1997) Tests of turtle phylogeny: Molecular, morphological, and paleontological approaches. Syst Biol 46: 235-268

Swofford DL (1993) Users Manual for PAUP Version 3.1: Phylogenetic Analysis Using Parsimony. Illinois Natural History Survey, Champaign, Illinois.

Thompson JD, Higgins DG, Gibson TJ (1994) CLUSTAL W: improving the sensitivity of progressive multiple sequence alignment through sequence weighting, position specific gap penalties and weight matrix choice. Nucl Acids Res 22: 4673-4680

Wada H, Makabe KW, Nakauchi M, Satoh N (1992) Phylogenetic relationships between solitary and colonial ascidians, as inferred from the sequence of the central region of their respective $18 \mathrm{~S}$ rDNA. Biol Bull 183: 448-455

(Received April 16, 1999 / Accepted May 20, 1999) 
APPENDIX-1. Specimens examined in this study. Iguana iguana: A South American species, from pet dealer, KUZ $37209^{*}$. Eumeces latiscutatus: Kyoto City, Japan, KUZ 46592*. Lygosoma bowringii: Khao Chong, Thailand, KUZ 37884*. Gekko gecko: Kaeng Krachan, Thailand, KUZ $35397^{*}$. Cyrtodactylus intermedius: Chantha Buri, Thailand, 32823*.

Rhacodactylus trachyrhynchus: A New Caledonian species, from pet dealer, KUZ 47440*.

Coleonyx mitratus: A central American species, from pet dealer, KUZ 47330, 47331*.

Aeluroscalabotes felinus: Sarawak, Malaysia, KUZ 27181*; one uncatalogued specimen.

Goniurosaurus sp.: From pet dealer (localities unknown), KUZ 34556, 34557*.

G. kuroiwae kuroiwae: Seiha, Chinen, southern part of Okinawajima, KUZ 8040*; Yona, Kunigami, northern part of Okinawajima, KUZ 21014*. G. k. orientalis: Shiroyama, lejima, KUZ 47418, 47441*.

G. k. splendens: Tete, Amagi, Tokunoshima, KUZ 33025*, 33030.

Eublepharis macularius: A Southwest Asian species, from pet dealer, KUZ 33169, 45197*.

Holodactylus africanus: An African species, from pet dealer, KUZ 45191, 45192*.

Hemitheconyx caudicinctus: An African species, from pet dealer, KUZ $32574^{*}$.

* Specimens, for which sequences are given in Appendix-2.

\section{APPENDIX-2.}

Aligned sequences of the mitochondrial DNA segment investigated. The initial $406 \mathrm{bp}$ in each row correspond to the $12 \mathrm{~S}$ rRA gene sequence, whereas the remaining $473 \mathrm{bp}$, marked with an asterisk at the beginning, correspond to the 16S rRNA gene sequence. Dot indicates an identity with the first sequence; dash denotes a gap. Abbreviations are: II, Iguana iguana; EL, Eumeces latiscutatus; LB, Lygosoma bowringii; GG, Gekko gecko; Cl, Cyrtodactylus intermedius; RT, Rhacodactylus trachyrhynchus; CM, Coleonyx mitratus; AF, Aeluroscalabotes felinus; GU, Goniurosaurus sp.; GS, G. kuroiwae splendens; GKN, G. k. kuroiwae from the northern part of Okinawajima; GKS, G. k. kuroiwae from the southern part of Okinawajima; GO, G. orientalis; EM, Eublepharis macularius; HA, Holodactylus africanus; HC, Hemitheconyx caudicinctus. Except for G. k. kuroiwae, each taxon is represented by a single specimen here (see Appendix-1).

11 GCTTAGACGTTAACAC-GACACCCCTC-CCAC-ATCGGTGTTCGCCAGAGAAATACTAGCGAAAAGCTTAAAACTCAAAGGACTTGGCGGTGCTCCACCCCGACTTAGAGGAGCCTGTCCTATAATCGATAATCCACGATAAACCTTACC

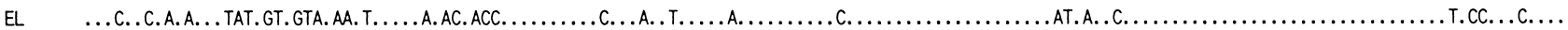

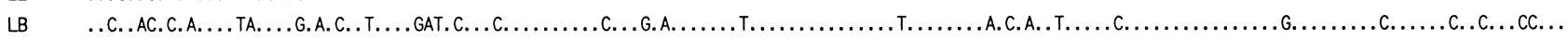

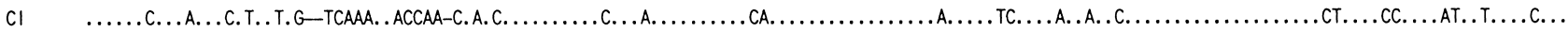

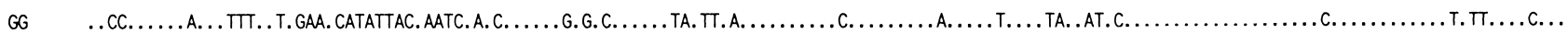

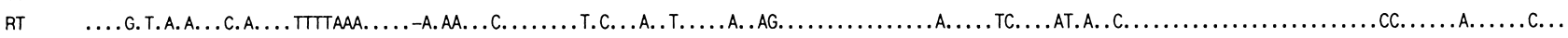

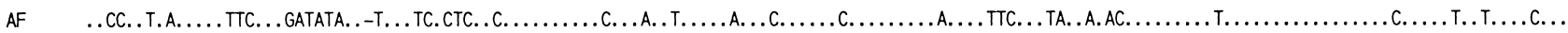

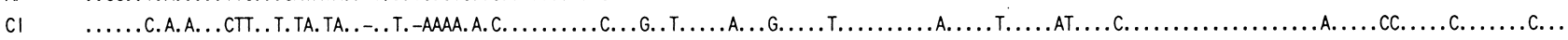

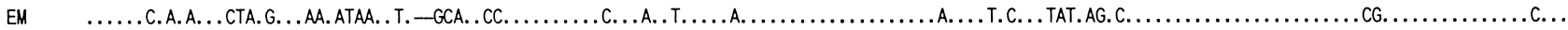

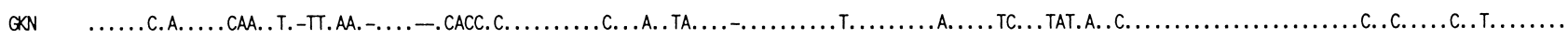

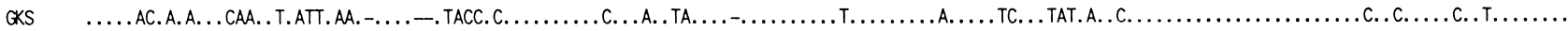

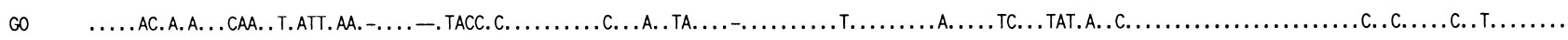

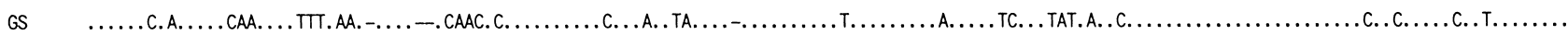

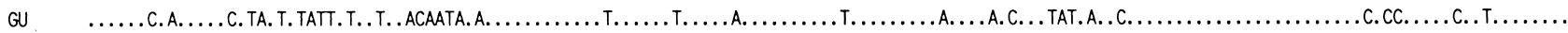

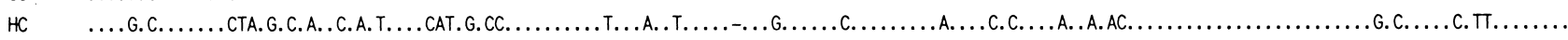

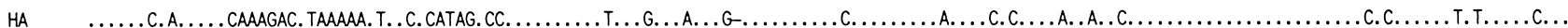

151

ATTाTTGCCAC--ATCAGCCTATATACCGCCGTCACCA-ACTTACCCCATGAGGGCCCAA-AAGTAAGTACAA-CAGTTTAACAACTAAAACGTCAGGTCAAGGTGTAGCTAATAAAATGG-AAGCGATGGGCTACATTTTTTAATA

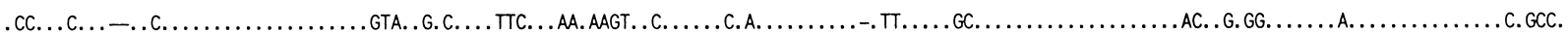

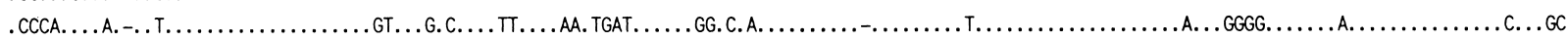

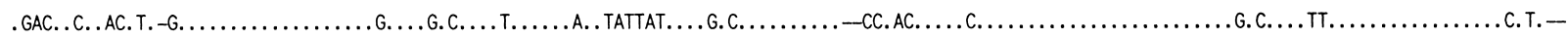

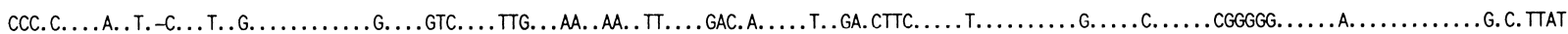

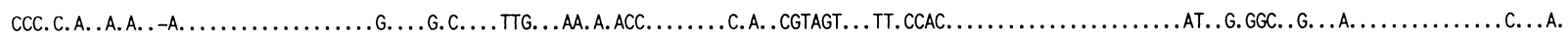

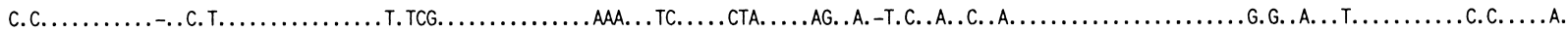

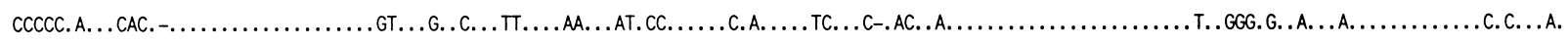

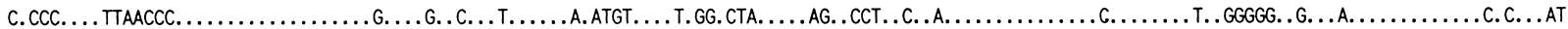

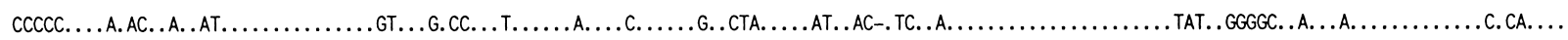

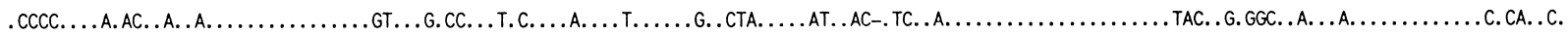

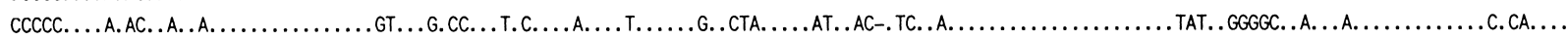

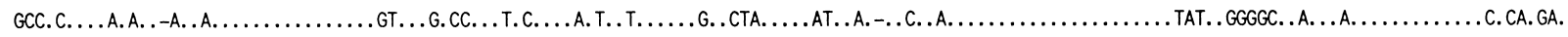

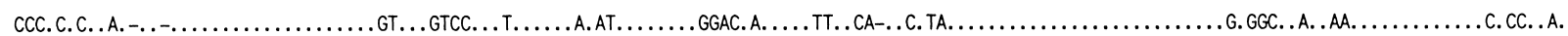

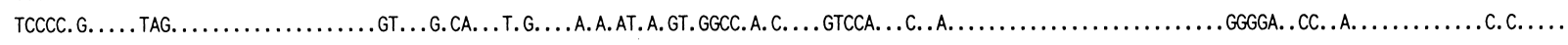

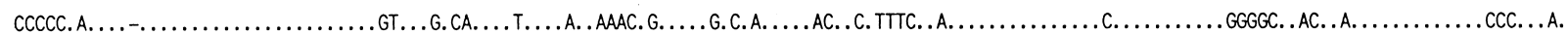


301

TAAAACATACGGCAAA--GTGCCATGAAACCGACACTA-GAAGGTGGATTTAATAGTAAGATAAGCGAGA-_-AGACTTATCTTAAACCCGCTCTGGAGCGCGCTGTCTCCTA-AATAGGG-ACTAGTATGAACGG-CTAAACGAGGG

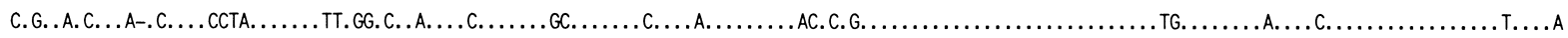

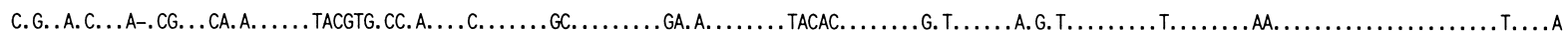

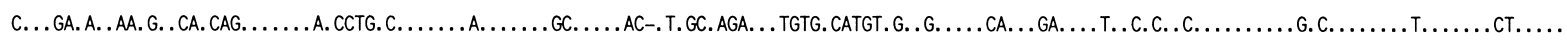

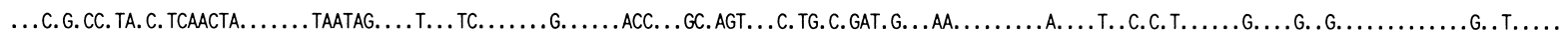

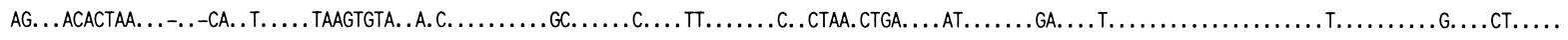

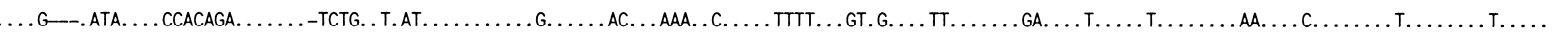

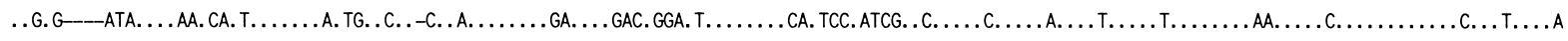

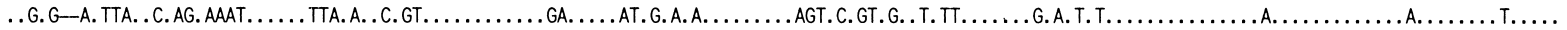

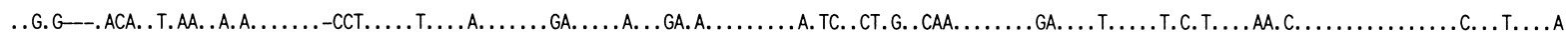

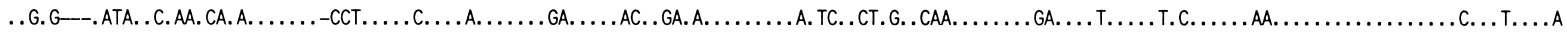

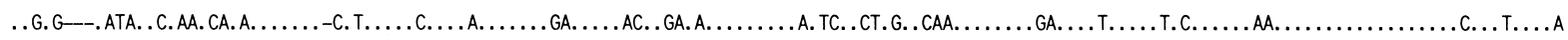

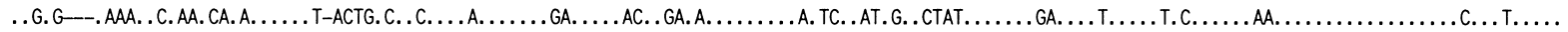

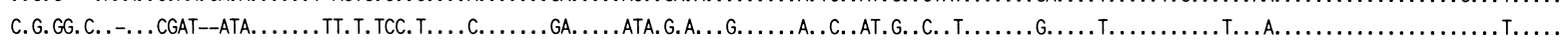

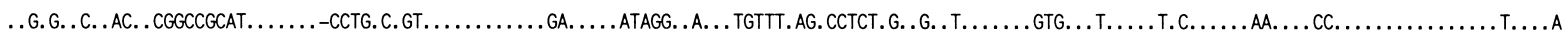

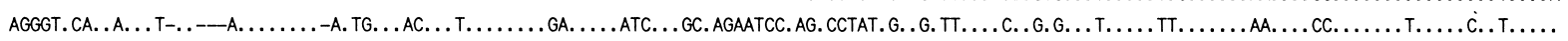

451 TTAACCTGTCTCCTTAGACCAATCAGTGAAACTGATCTGCCAGTACAAAAGCTGACATAGCAACATAAGACGAGAAGACCCTGTGGAGCTTTAGACTGACAGCCAAACCAAAACCACCCCACCTCAC

TTAACCTGTCTCCTTAGACCAATCAGTGAAACTGATCTGCCAGTACAAAAGCTGACATAGCAACATAAGACGAGAGGACCCTGTGGAGCTTAGACTGACAGCCAAACCAAAACCACCCCACCTCAC

$-C C$

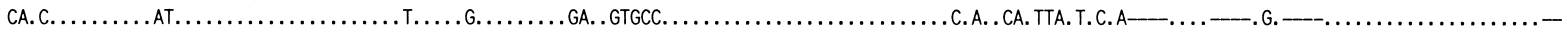

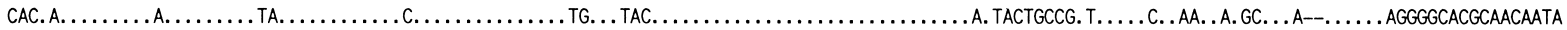

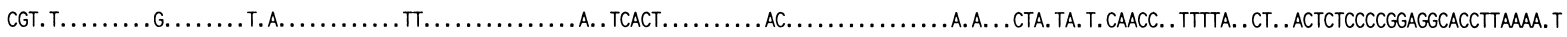

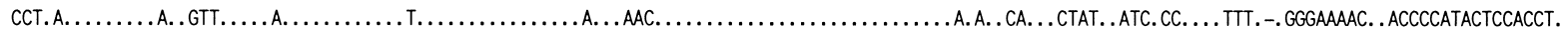

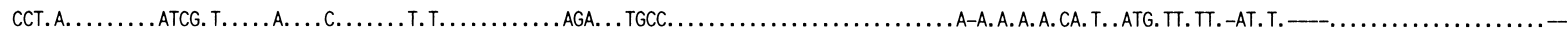

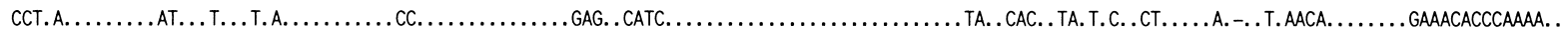

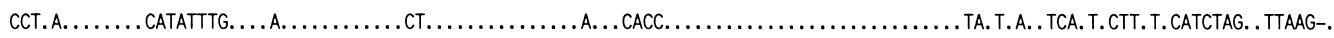

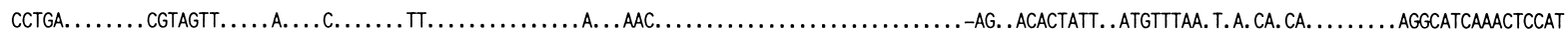

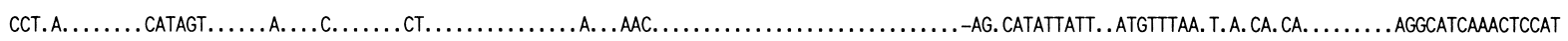

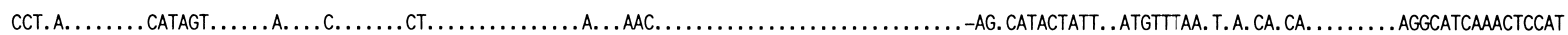

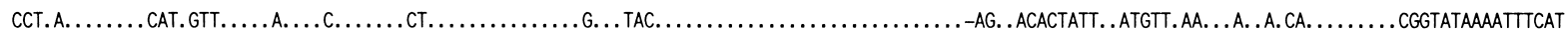

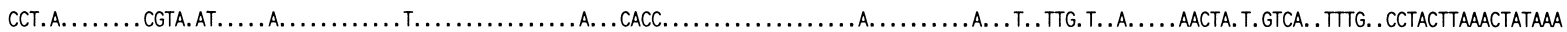

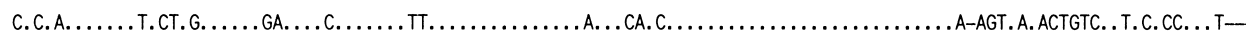

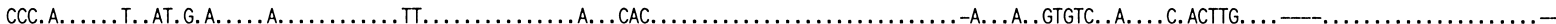
601

CATGGCTAAAAGT-CTTAAGTTGGGGGACTTCGGAGCAAAACAAAACCTCCAAGCAACAGAACATCCAT_-_-CTTCCCTAAGGCAAACACGCCAAAGCAA-_-ACAACA-_GACCCAGTA-CCACTGACCATCGAACCAAGTTAC

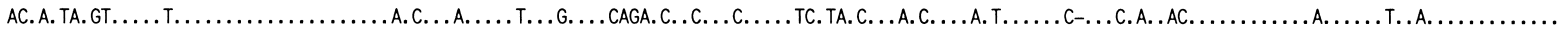

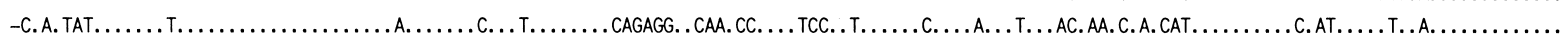

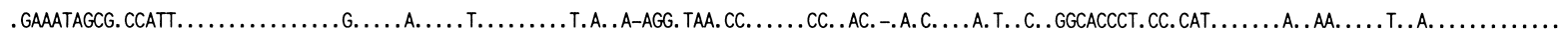

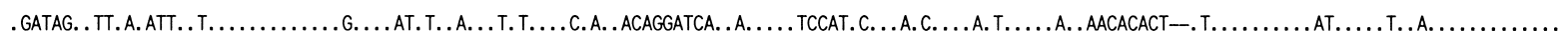

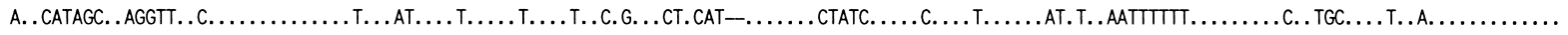

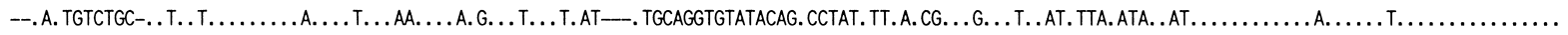

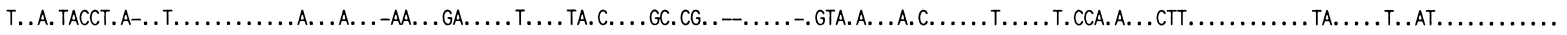

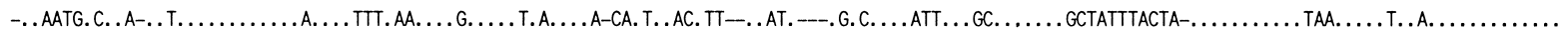

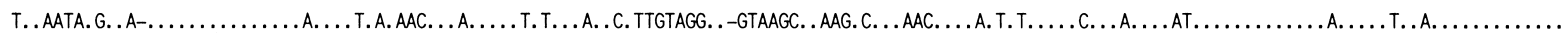

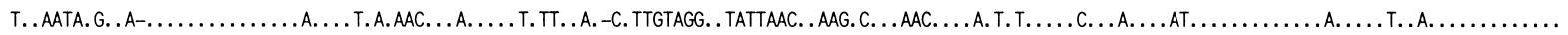

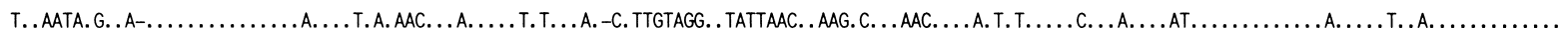

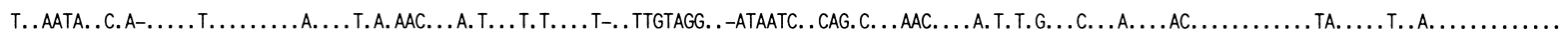

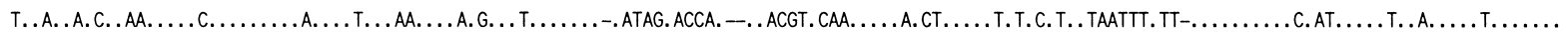

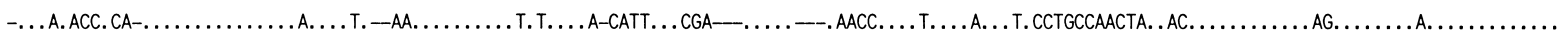

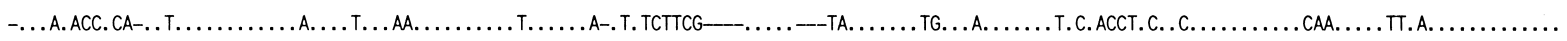

751

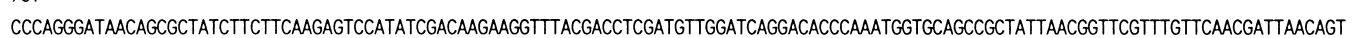

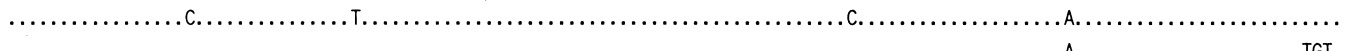
,

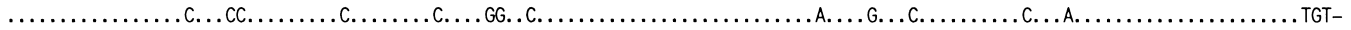

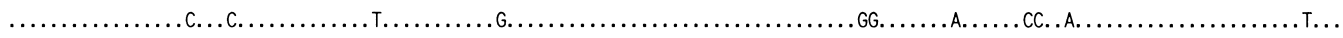

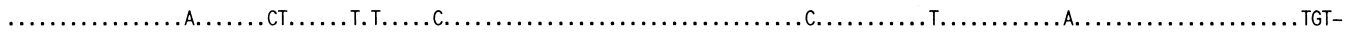

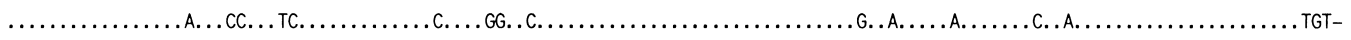

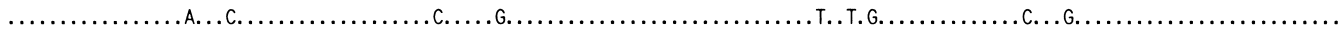

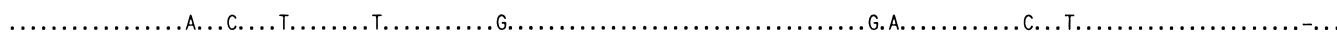

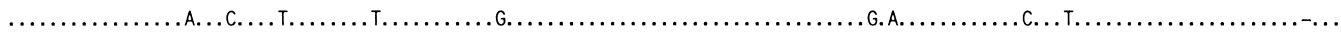

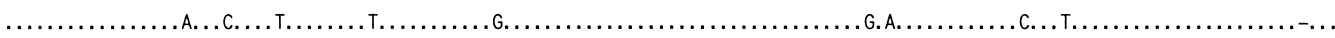

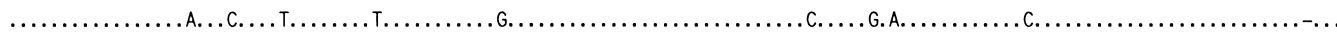

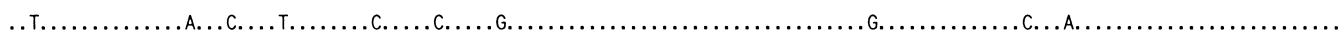

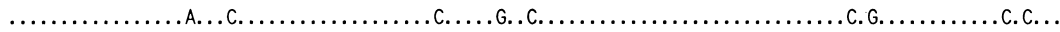
, 